Revision for International Journal of Greenhouse Gas Control

March 2016

\title{
Uncertainty Analysis of Carbon Sequestration in an Active $\mathrm{CO}_{2}$-EOR Field
}

Feng Pan ${ }^{1,2 *}$, Brian J. McPherson ${ }^{1,2}$, Zhenxue Dai ${ }^{3}$, Wei Jia ${ }^{1,2}$, Si-Yong Lee ${ }^{4}$, William Ampomah ${ }^{5}$, Hari Viswanathan ${ }^{3}$, Rich Esser $^{1,2}$

${ }^{1}$ Department of Civil \& Environmental Engineering, The University of Utah, Salt Lake City, UT 84112, USA

${ }^{2}$ Energy \& Geoscience Institute, The University of Utah, Salt Lake City, UT 84108, USA

${ }^{3}$ Earth and Environmental Sciences Division, Los Alamos National Laboratory, Los Alamos, NM 87545, USA

${ }^{4}$ Schlumberger Carbon Services, Denver, CO 80202, USA

${ }^{5}$ Petroleum Recovery Research Center, New Mexico Institute of Mining and Technology, Socorro, NM 87801, USA

*Corresponding author: Tel: +1 801587 5898; Fax: +1 801587 9148; Email address: fpan@egi.utah.edu 


\section{ABSTRACT}

Enhanced Oil Recovery (EOR) is perhaps the most feasible option for geologic $\mathrm{CO}_{2}$ sequestration (GCS). However, the typical large extent of uncertainty in reservoir properties is a major obstacle to effective risk assessment of GCS. The primary objective of this study was to quantify uncertainties in key reservoir parameters for an active, commercial-scale $\mathrm{CO}_{2}$-EOR field. We selected the Morrow formation within the active Farnsworth Unit (FWU) EOR field in Texas for this case study. Critical for this study are historical and real-time $\mathrm{CO}_{2}$ injection/production data as well as fundamental hydrologic and geologic characterization data from injection wells and three dedicated characterization / observation wells. We designed and applied a response surface methodology (RSM) integrated with Monte Carlo simulations to evaluate and quantify uncertainty. Previous sensitivity studies identified critical uncertain parameters including reservoir permeability, anisotropy ratio of permeability $\left(k_{v} / k_{h}\right)$, water-alternating-gas (WAG) time ratio, and initial oil saturation. Cumulative oil production, net $\mathrm{CO}_{2}$ storage, net water stored (difference between the injection water and produced water), and reservoir pressure at the injection well were the primary dependent variables used to evaluate uncertainties of $\mathrm{CO}_{2}$ storage associated with oil production and potential risk of 
reservoir pressure build-up. A 3-D static reservoir model was constructed based on the geology of the Farnsworth EOR site, serving as the basis for all multiple-realization reservoir simulations. After performing stepwise regression analyses, a series of response surface models of the dependent variables at each time step were constructed and validated using appropriate goodness-of-fit measures. Given the range of uncertainties in the independent variables, cumulative distribution functions (CDFs) and uncertainty bounds ( $5^{\text {th }}$ and $95^{\text {th }}$ percentiles) of output responses were estimated based on regression equations and Monte Carlo sampling. Forecasted cumulative oil production and net $\mathrm{CO}_{2}$ storage varied from $54,696 \mathrm{bb}$, and 22,784 tonnes, respectively, at the $5^{\text {th }}$ percentile to $203,989 \mathrm{bbl}$, and 39,525 tonnes at the $95^{\text {th }}$ percentile after 5 years. These results suggest that a significant proportion of forecasted output response uncertainty, including forecasted storage capacity, is propagated from parameter uncertainties. For this case study, response surface results suggest that maximum cumulative oil production could be achieved with permeability in a specific range $(10.0$ to $31.6 \mathrm{mD}$, which is close to the mean value of the actual strata). The pressure near the injection well exceeded $40 \mathrm{MPa}$, and $54 \mathrm{MPa}$ at the $95^{\text {th }}$ percentile after 1 and 5 years, respectively. The reservoir pressure fracturing threshold is just under $37 \mathrm{MPa}$ in the FWU, indicating a significant risk of caprock fracturing in the low permeability zones due to pressure build-up.

Keywords: $\mathrm{CO}_{2}$ sequestration; Enhanced oil recovery; Uncertainty quantification; Response surface methodology; Pressure buildup 


\section{INTRODUCTION}

Injection of $\mathrm{CO}_{2}$ for enhanced oil recovery (EOR), or " $\mathrm{CO}_{2}-\mathrm{EOR}$," is a proven tertiary technique for improving production of reservoirs considered "depleted" following secondary water-flooding. As such, $\mathrm{CO}_{2}-\mathrm{EOR}$ is considered to be one of many options for geologic $\mathrm{CO}_{2}$ sequestration. We suggest that effective quantification of risks associated with long-term $\mathrm{CO}_{2}$ storage following $\mathrm{CO}_{2}$-EOR can be achieved with accurate and robust quantification of associated uncertainty. And, we suggest that the most significant source of uncertainty for $\mathrm{CO}_{2}$-EOR is geological information and specifically reservoir parameters (properties).

In general, $\mathrm{CO}_{2}$-EOR uncertainty sources may be classified as geological, physical and operational (Ashraf et al., 2013; Yang et al., 2014). Geological uncertainties associated with heterogeneity have attracted significant attention in recent years, with many studies suggesting heterogeneity as the primary source of uncertainty in model forecasts of $\mathrm{CO}_{2}$ storage capacity, $\mathrm{CO}_{2}$ plume extent, $\mathrm{CO}_{2}$ migration and storage performance, and $\mathrm{CO}_{2}$ leakage (Deng et al., 2012; Li and Zhang, 2014; Tian et al., 2014; Dai et al., 2014a; Liu and Zhang, 2011). Probabilistic analysis is a robust approach to quantify such geological uncertainties and how they propagate to risk assessment results, typically in the form of specific probability density functions (PDFs) for key uncertain input parameters. Monte Carlo methods are conceptually straightforward, with successful uncertainty assessment of both linear and nonlinear flow and transport problems (Pan et al., 2009a, 2009b; Ye et al., 2007). However, typical Monte Carlo methods are computationally expensive as they require a large number of model simulations. Recently, several studies applied polynomial chaos expansion (PCE) to quantify risks of geological 
$\mathrm{CO}_{2}$ storage (GCS) (Zhang and Shinidis, 2013; Oladyshin et al., 2011; Ashraf et al., 2013; Oladyshkin et al., 2010). The PCE approach was first introduced by Wiener (1938) to determine the evolution of uncertainty in dynamic systems based on homogenous chaos theory. The PCE method was extended to analysis of stochastic processes using Hermite polynomial chaos for Gaussian random variables by Ghanem and Spanos (1991), and then adapted to generalized polynomial chaos with a Winer-Askey scheme for a number of continuous and discrete random distributions by Xiu and Karniadakis (2002). The intrusive PCE approach substitutes PCE approximations into the governing equation to solve its coefficients (in the expansion) using a Galerkin technique. Since multiphase flow and transport processes in $\mathrm{CO}_{2}$-EOR fields involve strongly non-linear fluid properties and phase changes, it is very difficult to implement the intrusive PCE approach. While the nonintrusive PCE approach does not change the governing equations, it solves for the expansion coefficients by choosing collocation points. In other words, the PCE model must be iteratively built and evaluated for all collocation points for every expansion degree increase. This may substantially increase computational cost and therefore limit applicability of the nonintrusive PCE approach.

Another approach to quantify uncertainty of complex subsurface multiphase flow and transport processes is the Response Surface Method, or RSM. A RSM illustrates the relationship between the response variable yield (i.e., performance measure or quality characteristics of the products or processes) and one or more independent variables (i.e., input variables) (Myers and Montgomery, 2002, Bacon et al., 2015). The RSM has been recently applied to geologic $\mathrm{CO}_{2}$ storage processes, including caprock failure assessment due to $\mathrm{CO}_{2}$ storage (Rohmer and Bouc, 2010; Wriedt et al., 2014); $\mathrm{CO}_{2}$ flooding design 
optimization for $\mathrm{CO}_{2}$-EOR (Ghomian et al., 2010; Yao and Ji, 2010; Dai et al., 2014b); uncertainty assessment of $\mathrm{CO}_{2}$ storage in deep saline aquifers (Liu and Zhang, 2011); and uncertainty quantification of $\mathrm{CO}_{2}$ sequestration with oil recovery (Dai et al., 2014a, 2014c). Compared to the computational-expensive conventional Monte Carlo approach and the relatively difficult implementation of the PCE approach, the RSM was adapted in this study to quantify uncertainties of key parameters associated with $\mathrm{CO}_{2}$ sequestration and oil recovery.

The case study site selected for analysis was the Farnsworth Unit (FWU) $\mathrm{CO}_{2-}$ EOR field in Ochiltree County, Texas (Figure 1), operated by Chaparral Energy, L.L.C. (CELLC). The FWU site is an active $\mathrm{CO}_{2}-\mathrm{EOR}$ project, and is the primary of the Southwest Regional Partnership on Carbon Sequestration (SWP) Phase III project, sponsored and facilitated by the U.S. Department of Energy and its National Energy Technology Laboratory. The FWU started initial oil production in the mid 1950's with secondary production (water flooding) beginning in the 1960's. Chaparral Energy began $\mathrm{CO}_{2}$ injection in December 2010; injection is presently ongoing in thirteen individual inverted five-spot well patterns; Chaparral intends to drill three to five new patterns each year until a total of about 25 patterns are operational (depending on oil prices). Present and planned future net $\mathrm{CO}_{2}$ injection at the FWU is $0.3277 \mathrm{sm}^{3} / \mathrm{s}(\sim 190,000$ tonnes/yr), requiring just over five years to inject 1 million tonnes of new $\mathrm{CO}_{2}$. By May 2015, a total of about 786,000 tonnes of purchased $\mathrm{CO}_{2}$ has been injected among 13 unique wells in the FWU. For a commercial-scale $\mathrm{CO}_{2}$-EOR field such as the $\mathrm{FWU}, \mathrm{CO}_{2}$ injection into the subsurface includes potential risks of pressure buildup, formation damage, induced seismicity, and possible fluid leakage to the overlying Ogallala aquifer. While initial 
analyses indicate that these risks are low at the FWU, quantitative assessment requires robust evaluation of parameter (geological) uncertainties.

The objectives of this study include: (1) quantification of key geologic parameter uncertainties for an active, commercial-scale $\mathrm{CO}_{2}$-EOR field; and (2) investigation of the effects of specific uncertain independent variables on key output responses including oil production, net $\mathrm{CO}_{2}$ storage, net water stored (difference between the injection water and produced water), and pressure evolution next to the injection well. The National Risk Assessment Partnership (NRAP) is focusing much of its effort on using RSM for developing reduced order models for mitigating the computational expense of risk assessment. This study was in collaboration with NRAP researchers.

\section{MATERIALS and METHODS}

\subsection{Study Site}

The Farnsworth EOR target is the Morrow formation, an incised valley-fill sandstone reservoir that extends from eastern Colorado and western Kansas through Oklahoma into the Texas panhandle (Munson, 1989) (Figure 1). Within the FWU, the predominant lithology of the Morrow formation is coarse-grained sandstone. The Morrow is overlain by the Thirteen Finger limestone (Gallagher, 2014). The FWU Morrow formation has an average depth of 2,362 m, ranging from 2,300 m to 2,423 m; its average dip is less than one degree (Ampomah et al., 2015). All $\mathrm{CO}_{2}$-EOR activities are in the western half of the FWU. Measurements of Morrow core permeability vary from 0.1 to $700 \mathrm{mD}$ with an average of $44.3 \mathrm{mD}$ in the western half of the FWU; corresponding average porosity is 0.14 (range: 0.029 to 0.21 ). The permeability and 
porosity data are direct measurements on drill core from 17 wells in the western half of the field. Based on preliminary estimates of formation volume and porosity, $\mathrm{CO}_{2}$ storage capacity of the Morrow within the FWU exceeds 10 million tonnes, translating to over 50 years of storage capacity at the current 190,000 tonnes per year rate of $\mathrm{CO}_{2}$ transported to the FWU from two sources, an ethanol plant in Kansas and a fertilizer plant in Texas.

\subsection{Response Surface Methodology (RSM)}

The RSM is a popular approach for quantifying uncertainty of complex multiphase flow and transport processes in the subsurface. The RSM integrated with Monte Carlo sampling requires an effective numerical experiment design, followed by reservoir simulations, stepwise regression analysis, and Monte Carlo simulations. The most commonly used designs of numerical experiments for RSM are full and fractional factorial designs, central composite design, Box-Behnken design (BBD), Doehlert and mixture designs (see Ferreira et al., 2007, for an effective summary). Among them, the $\mathrm{BBD}$ is widely used because it typically requires fewer simulations than other designs. We selected the BBD approach for this study. Our BBD was developed based on threelevel incomplete factorial designs (Ferreira et al., 2007), which consists of three levels (-1, $0,1)$ corresponding to lower, middle, upper endpoint of each factor for fitting the secondorder response surface (Box and Wilson, 1951; Myers and Montgomery, 2012). Each factor was placed at one of the three equally spaced values. The BBD generally requires $2 k(k-1)+1$ experimental points (runs) (Ferreira et al., 2007).

The workflow of the RSM with Monte Carlo sampling implemented in this study was as follows: (1) determination of the independent variables/factors to construct the design of the experiment based on the BBD; (2) conduct a small number of numerical 
simulations with physically-based models based on the numerical experimental design; (3) delineate system responses due to $\mathrm{CO}_{2}$ injection by constructing the response surface (or proxy) model for each time step; (4) utilize a stepwise regression technique to eliminate insignificant factors from the regression equation; (5) Monte Carlo sampling of mutually independent input parameters through the obtained response surface models; (6) generate temporal evolution for each time step in the cumulative distribution functions (CDFs) of output responses from the given input distributions.

A second-degree polynomial model is suggested to obtain an optimal response from the designed experiments in the RSM. The relationship between the response (y) and the input variables $\left(X_{i}\right)$ in a design of experiment may be expressed as:

$$
\mathrm{y}=\beta_{0}+\sum_{\mathrm{i}=1}^{\mathrm{k}} \beta_{\mathrm{i}} \mathrm{X}_{\mathrm{i}}+\sum_{\substack{\mathrm{i}=1, \mathrm{j}=2 \\ \mathrm{i}<\mathrm{j}}}^{\mathrm{k}} \beta_{\mathrm{ij}} \mathrm{X}_{\mathrm{i}} \mathrm{X}_{\mathrm{j}}+\sum_{\mathrm{i}=1}^{\mathrm{k}} \beta_{\mathrm{ii}} \mathrm{X}_{\mathrm{i}}^{2}+\varepsilon,
$$

where $\beta_{i}, \beta_{i j}$, and $\beta_{i i}$ represent regression coefficients and $\varepsilon$ is random error assumed to have a zero mean; $k$ is the number of input variables. A nonlinear regression method was used to determine the coefficients of the polynomial/response surface model at each time step in Eq. (1). The least squares estimator of beta is:

$$
\widehat{\beta}=\left(X^{\prime} X\right)^{-1} X^{\prime} y \quad .
$$

After performing stepwise regression modeling, a series of response surface models at each time step (Eq. 1) are identified. The coefficient of determination $\left(R^{2}\right)$ and normalized root mean square error (NRMSE) are used to examine and verify the efficacy of response surface models for predictions (i.e., compared to the physically-based reservoir models). Specifically, additional multiple runs of model simulations are conducted, and the developed response surface models are compared to the original physical-based models. Finally, 10,000 realizations of Monte Carlo samples of the input 
variables are applied to the developed response surface models, resulting in probabilistic distributions of output variables. For this study, we selected four output responses for analysis, including cumulative oil production, net $\mathrm{CO}_{2}$ storage, net water stored, and fluid pressure close to the injection well. We suggest that fluid pressure next to the injection well may be considered by many to be a risk (process) as well, and thus we consider this analysis to be the beginning stage of a formal risk assessment for the FWU.

\subsection{Uncertain Independent Variables}

We selected four critical independent variables including reservoir permeability, permeability anisotropy ratio (vertical and horizontal directions, $k_{v} / k_{h}$ ), WAG time ratio (ratio of $\mathrm{CO}_{2}$ injection time to water injection time), and initial oil saturation (Table 1). This selection of specific uncertain input parameters was based on a sensitivity analysis from a previous study (Dai et al., 2014a, 2014b). Permeability was assumed to follow a lognormal distribution, and a uniform distribution was assigned for the other three variables. Statistics of these parameters are based on site characterization data, including well logs and core analyses from the Morrow formation of the FWU. The estimated mean and standard deviation of permeability from 702 measurements in 17 wells of the western half of the field are 1.044 and 0.765 , respectively. The lower, middle, and upper endpoint of the permeability values in Table 1 are $\mu-2 \sigma, \mu$, and $\mu+2 \sigma$, respectively. The WAG time ratio was analyzed based on measured WAG injection data of Well \#13-9 in the Farnsworth Unit for January 2014 to October 2014. The average WAG time ratio for Well \#13-9 was 1.59 (range: 1.08 to 2.95). The lower and middle endpoints of the WAG time ratio are 1.0 and 1.5 , respectively. Since the WAG time ratio was assumed to follow a uniform distribution, its upper endpoint value was set as 2.0. Analysis of 175 core- 
based measurements in the FWU indicates that the anisotropy ratio $\left(k_{v} / k_{h}\right)$ varies from 0.1 to $1.0 ; 0.1,0.55$, and 1.0 were chosen as the lower, middle, and upper endpoints of anisotropy ratio of permeability, respectively. The average oil saturation of 0.28 was set as the middle endpoint with 0.19 and 0.37 as the lower and upper endpoints of oil saturation, respectively, based on measured saturation data for the field.

The relationship between porosity and permeability was analyzed based on the available data from Well \#13-10 within the western half of the FWU. An empirical equation (Porosity $=0.0187 * \ln ($ permeability $)+0.0924)$ was constructed; a corresponding $\mathrm{R}^{2}$ value of 0.83 (Figure 2) suggested that the empirical equation reasonably represented the relationship of porosity and permeability for the Morrow in this area of the Farnsworth Unit.

Given the three levels $(-1,0,1)$ for four independent variables in the BBD, a total of 25 runs were designed for the numerical experiments. Twenty five simulations with the Farnsworth 3-D reservoir model were conducted using the Eclipse E300 simulator (Schlumberger, 2012).

\subsection{Farnsworth 3-D Reservoir Model}

The 3-D static reservoir model of the Farnsworth Unit was constructed based on data from well logs and drill core, and an updated seismic interpretation (Ampomah et al., 2015). The Morrow $\mathrm{B}$ formation (the Farnsworth $\mathrm{CO}_{2}-\mathrm{EOR}$ target formation) was divided into 6 layers in the 3-D static model (Ampomah et al., 2015). Since all $\mathrm{CO}_{2}$-EOR operations are in the western half of the FWU, we utilized only the western half domain of the Farnsworth 3-D static reservoir model for this uncertainty quantification study. The 3-D static reservoir model for the western half of the FWU was constructed with a total 
of 202,120 cells $(163 * 155 * 8)$, with a cell size of $30.48 \mathrm{~m} \times 30.48 \mathrm{~m}$ in the horizontal direction (Figure 1). History matching was used to calibrate the reservoir model using both primary and secondary oil recovery (production) data (Ampomah et al., 2016).

One five-spot well pattern was simulated in the western-half model domain of FWU for all reservoir simulations. Well \#13-6 (Figure 1) is the production well with four injection wells, including \#13-1, \#13-9, \#13-10A, and \#13-13 (Figure 1). The Neumann (no-flow) boundary condition was assigned for all boundaries, allowing the wells to exclusively dictate hydrodynamics. Initial reservoir pressure was set hydrostatic, with a pressure of $31.03 \mathrm{MPa}$ assigned to the bottom of the model domain (White et al., 2014). A total of 6 years was simulated with a 5-year water-alternating- $\mathrm{CO}_{2}$ injection and a 1year monitoring and recovery period. Water injection initiated on January 1, 2011 at a constant rate of $1.0 \mathrm{l} / \mathrm{s}$, followed by $\mathrm{CO}_{2}$ injection at a constant rate of $0.063 \mathrm{sm}^{3} / \mathrm{s}$. The total injection time was 60 days for each water-alternating- $\mathrm{CO}_{2}$ injection cycle (a total of 30.4 cycles), and the specific duration of water and of $\mathrm{CO}_{2}$ injection in each cycle varies according to the WAG time ratio. Water and $\mathrm{CO}_{2}$ injection rates are adopted based on average rates for Well \#13-9 (Figure 1) from January 2014 to October 2014. Since the EOR operation in this study uses tertiary recovery, the initial gas saturation was set as zero. The water saturation was calculated as 1.0 - oil saturation, and varied from 0.63 to 0.81. We assume the oil and water saturation are homogeneous in the entire model domain since only one five-spot well pattern was adopted with the same wells during the secondary recovery.

The Eclipse E300 simulator (Schlumberger, 2012) was used in this study to perform all 3-D reservoir simulations. Based on the numerical experimental design, 25 
runs of 3-D reservoir simulations were conducted and the response surface models between the input variables and output responses were constructed based on the numerical simulation results. The computation time varied from 1.3 hours to approximately 26 hours for the 25 runs of 3-D reservoir simulations using a Windows Workstation with Intel® Xeon® CPU @ 2.00GHz and 128 GB memory. Thus, we elected to construct response surface models for computational efficiency.

\section{RESULTS}

\subsection{Goodness-of-Fit and Validation}

Using stepwise regression modeling, a series of response surface models between the independent input variables and output responses at each time step were constructed. The coefficient of determination $\left(R^{2}\right)$ and normalized root mean square error (NRMSE) were used to examine the efficacy of response surface models for the predictions (e.g., compared to the original physically-based reservoir model). Figure 3 plots simulated (using original reservoir model) and emulated (using regression model) cumulative oil production, net $\mathrm{CO}_{2}$ storage, net water stored and pressure next to the injection well after 5 years of water-alternating- $\mathrm{CO}_{2}$ injection. Figure 3 suggests that the emulated values match reasonably well with the simulated values; specifically, the $\mathrm{R}^{2}$ values for cumulative oil production, net $\mathrm{CO}_{2}$ storage, net water stored, and pressure next to the injection well are $0.989,0.992,0.996$, and 0.993 , respectively. The values of NRMSE are $3.4 \%$ for cumulative oil production, $2.3 \%$ for net $\mathrm{CO}_{2}$ storage, $1.7 \%$ for net water stored, and $2.8 \%$ for pressure next to the injection well. Simulated output responses also match reasonably well with emulated values using regression models after 1, 2, 3, and 4 years of 
simulations (figures not shown). Their $\mathrm{R}^{2}$ values are larger than 0.9, and NRMSE values are less than $5 \%$, indicating that the response surface models will provide reasonable forecasts (predictions).

It was also necessary to validate whether the results with response surface models adequately represented the results of the original physical-based reservoir model. An additional 10 runs of the 3-D reservoir simulations were conducted, and 10-realization input samples were randomly selected from a total of 10,000 Monte Carlo samples of the input variables. The emulated and simulated output responses from the 10 validation cases (in delta dot) are also plotted in Figure 3. Emulated output responses using response surface models exhibit good agreements with the original reservoir simulations for the 10 validation cases (delta dots in Figure 3 ). The $\mathrm{R}^{2}$ values for the 10 validation cases are 0.992, 0.993, 0.988, and 0.977 for cumulative oil production, net $\mathrm{CO}_{2}$ storage, net water stored, and pressure next to the injection well, respectively. The corresponding NRMSE values are $3.14 \%, 2.67 \%, 4.74 \%$, and $7.76 \%$, respectively. The large $\mathrm{R}^{2}$ and small NRMSE for the 10 validation cases illustrate that the constructed response surface models are quantitatively consistent with the original, physically-based reservoir models for estimations of the selected output responses.

\subsection{Uncertainty Assessment of $\mathrm{CO}_{2}$ Storage and Oil Recovery}

Ten thousand realizations of Monte Carlo samples of the input variables were applied to the developed response surface models, resulting in probabilistic distributions of output variables. Figure 4 depicts the CDFs of cumulative oil production, net $\mathrm{CO}_{2}$ storage, net water stored, and pressure next to the injection well after 1, 2, 3, 4, and 5 years of simulation. Table 2 also lists the $5^{\text {th }}, 25^{\text {th }}, 50^{\text {th }}, 75^{\text {th }}$, and $95^{\text {th }}$ percentiles of the 
output responses after 1 , and 5 years of simulations. The mean values of cumulative oil production at the end of $1,2,3,4$, and 5 years are $22,801 \mathrm{bbl}, 47,287 \mathrm{bbl}, 74,348 \mathrm{bbl}$, $102,752 \mathrm{bbl}$, and 130,993 bbl, respectively. The annual increase of oil production varies from 24,485 bbl to $28,241 \mathrm{bbl}$, indicating a similar oil production rate for each year. The uncertainty bounds of the cumulative oil production increase over time. For example, the emulated cumulative oil production varies from $5,866 \mathrm{bbl}$ at the $5^{\text {th }}$ percentiles, 22,797 bbl at $50^{\text {th }}$ percentiles, to $36,368 \mathrm{bbl}$ at $95^{\text {th }}$ percentiles after 1 year of simulation. The corresponding values for the cumulative oil production at the $5^{\text {th }}, 50^{\text {th }}$, and $95^{\text {th }}$ percentiles at the end of 5 years are 54,696 bbl, 131,061 bbl, and 203,989 bbl, respectively (Table 2). The $90^{\text {th }}$ percentile intervals (differences between $5^{\text {th }}$ and $95^{\text {th }}$ percentiles) of emulated cumulative oil production are 30,532, and 149,293 bbl after 1 and 5 years, respectively. These results suggest that the significant uncertainties of cumulative oil production are propagated from the input parameter uncertainties. The average oil production rates in the $4^{\text {th }}$ year of the simulations (i.e., 2014) range from 39.5 $\mathrm{bbl} / \mathrm{day}$ at the $5^{\text {th }}$ percentile to $121.3 \mathrm{bbl} / \mathrm{day}$ at the $95^{\text {th }}$ percentile. Comparison to limited field data in 2014 illustrate that oil production rates at Well \#13-6 varies from 48.5 $\mathrm{bbl} / \mathrm{day}$ to $98.3 \mathrm{bbl} / \mathrm{day}$, which falls within the range of uncertainty bounds of the emulated oil production rates for that year.

Similar characteristics are also observed for net $\mathrm{CO}_{2}$ storage and net water stored (Figure 4). The average values of net $\mathrm{CO}_{2}$ storage for each year are 6,169 to 6,489 tonnes, and the mean of annual net water stored ranges from 361 to $372 \mathrm{Mbbl}$, both small differences annually. Net $\mathrm{CO}_{2}$ storage after 5 years of water-alternating- $\mathrm{CO}_{2}$ injection varies from 22,784 tonnes at the $5^{\text {th }}$ percentile to 39,525 tonnes at the $95^{\text {th }}$ percentile 
(Table 2). The 90th percentile intervals of net water stored after 1 and 5 years are 0.20 and $0.94 \mathrm{MMbbl}$, respectively (Table 2). This indicates that significant uncertainties of net $\mathrm{CO}_{2}$ storage and net water stored are propagated from parameter uncertainties.

Figure 4 illustrates that the average values of emulated pressure next to the injection well after 1, 2, 3, 4, and 5 years of simulations are 33.6, 35.0, 36.0, 36.7, and 37.3 $\mathrm{MPa}$, respectively. Pressure next to the injection well increases over time with continuous injection of water-alternating- $\mathrm{CO}_{2}$. Specifically, reservoir pressure at the injection well may increase from an initial pressure of $30.0 \mathrm{MPa}$ to $40.0 \mathrm{MPa}$ at the $95^{\text {th }}$ percentile after 1 year of simulation. The $5^{\text {th }}$ percentile of emulated pressure next to the injection well was only 30.4, 30.6, 30.6, 30.4, and 30.5 MPa after 1, 2, 3, 4 and 5 years of simulations, respectively. The corresponding values of the $95^{\text {th }}$-percentile pressure next to the injection well are 40.2, 45.2, 49.0, 52.0, and 54.2 MPa, respectively. Geomechanical studies of the FWU suggest that the caprock fracture pressure threshold for the Thirteen Fingers Formation is approximately 36.5 MPa. The pressure threshold of $36.5 \mathrm{MPa}$ can be reached at the $83^{\text {rd }}$ percentile, $72^{\text {nd }}$ percentile, $65^{\text {th }}$ percentile, $62^{\text {nd }}$ percentile, and $59^{\text {th }}$ percentile after 1, 2, 3, 4 and 5 years of simulations, respectively (Figure 4 and Table 2). These results suggest that caprock fracturing is possible as a result of pressure build-up after continuous water-alternating- $\mathrm{CO}_{2}$ or so-called "WAG" injection. To reduce the risk of pressure build-up and caprock fracturing, additional site characterization should be conducted to reduce the uncertainty of rock properties and guide the operator toward optimization of water-alternating- $\mathrm{CO}_{2}$ injection. 


\subsection{Response Surface Analysis}

Figure 5 provides the response surfaces of cumulative oil production after 1 year and 5 years in relation to the uncertain input variables of log permeability and initial oil saturation. At the end of 1 and 5 years of simulation, cumulative oil production increases with the increase of log permeability and reaches its maximum value when permeability varies between 10.0 and $31.6 \mathrm{mD}$ (i.e., $\log$ permeability at 1.0-1.5 in Figure 5). With a continued increase of permeability, cumulative oil production decreases at the end of 1 and 5 years of simulation. The largest cumulative oil production occurred when permeability was close to the mean value of actual strata; with lower and higher values of permeability, decreased cumulative oil production results. When permeability was assigned as relatively high, corresponding pressure buildup was relatively small, and resulted in reduced pressure gradients between the injection and production wells. Although high permeability leads to early $\mathrm{CO}_{2}$ breakthrough, smaller pressure gradients result in a reduced amount of cumulative oil production over a longer time. When permeability was assigned as very low, reduced oil flow rates and oil production resulted, although the pressure gradients between the injection and production wells were large for some grid points in the model. Figure 5 also illustrates that cumulative oil production increases with higher initial oil saturation (higher initial oil saturation means more oil stored in the reservoir).

Figure 6 depicts the response surfaces of the net $\mathrm{CO}_{2}$ storage and net water stored after 5 years in relation to the uncertain input variations of log permeability and wateralternating-gas or WAG time ratio (ratio of $\mathrm{CO}_{2}$ injection time to water injection time). The effects of permeability on net $\mathrm{CO}_{2}$ storage exhibit similar patterns as for oil 
production, shown in Figure 5, but reverse impacts compared to cumulative oil production. At the end of 5 years of injection, net $\mathrm{CO}_{2}$ storage decreases with increased permeability, and its minimum was observed at permeabilities between 10-31.6 mD (i.e., $\log$ permeability at $1.0-1.5$ in Figure 6). The smallest net $\mathrm{CO}_{2}$ storage appears at $\log$ permeabilities of $1.0-1.5 \mathrm{mD}$ (Figure 6), and this permeability condition provides maximum oil production (Figure 5) because $\mathrm{CO}_{2}$ production increases with oil production. When $\mathrm{CO}_{2}$ injection was constant for a certain WAG time ratio, net $\mathrm{CO}_{2}$ storage was small with large $\mathrm{CO}_{2}$ production. One can also see from Figure 6 that the effects of permeability on the net $\mathrm{CO}_{2}$ storage with low and high WAG time ratios are more significant than those with the mean WAG time ratio. This suggests that the high and low WAG time ratio accentuate the effects of permeability on the net $\mathrm{CO}_{2}$ storage. The large relative permeability of $\mathrm{CO}_{2}$ /water with high/low WAG time ratio could result in a significant impact of permeability on the net $\mathrm{CO}_{2}$ storage. The net $\mathrm{CO}_{2}$ storage increases with an increase of WAG time ratio (Figure 6), because larger WAG ratios mean longer $\mathrm{CO}_{2}$ injection periods and more $\mathrm{CO}_{2}$ injected with a constant injection rate. The uncertain parameter, anisotropy ratio of permeability, has very limited effects on the net $\mathrm{CO}_{2}$ storage (figure not shown). At the end of the 5-year injection, net water stored decreases with an increase of log permeability (Figure 6); water production at the end of the 5-year injection increases with log permeability for a given WAG time ratio (i.e., the same water injection). The relationship between the net $\mathrm{CO}_{2}$ storage and input parameters could guide us to conduct additional site characterization and monitoring efforts to reduce the uncertainty of the $\mathrm{CO}_{2}$ storage performance. 
Figure 7 shows the response surfaces for pressure next to the injection well after 1 year and 5 years in relation to the uncertain input variables of log permeability and WAG ratio. The highest pressure next to the injection well occurs at the smallest permeability values at the end of 1 and 5 years of injection. As permeability increases, reservoir pressure next to the injection well generally decreases from $40.0 \mathrm{MPa}$ at the end of 1 year and 60.0 MPa at the end of 5 years to the initial pressure of $30.0 \mathrm{MPa}$. Effectively, lower permeability leads to higher pressure buildup around the injection well (Wainwright et al., 2013). The effects of WAG time ratio on the pressure build-up are relatively limited except in the low permeability zone. Given the pressure threshold of $36.5 \mathrm{MPa}$ in the FWU caprock, the significant pressure build-up in the lower permeability zone could risk caprock facture. The relationship of pressure build-up with the rock properties (permeability) and operational parameters (WAG injection scheme) shown in Figure 7 could guide decision making and risk management to reduce the potential risk of reservoir pressure build-up to avoid the caprock integrity failure and $\mathrm{CO}_{2}$ leakage.

\section{SUMMARY AND CONCLUSIONS}

The RSM approach and Monte Carlo sampling were integrated in this study to quantify uncertainties of key parameters associated with $\mathrm{CO}_{2}$ storage and oil production in an active $\mathrm{CO}_{2}$-EOR field. A series of response surface models that represent the relationships between the independent and dependent variables at each time step were constructed and verified using appropriate goodness-of-fit measures (i.e., $\mathrm{R}^{2}$ and NRMSE). The developed response surface models were also validated with an additional 10 realizations of reservoir simulations. The 10,000 realizations of Monte Carlo samples 
of the input variables were applied to the developed response surface models, resulting in the probabilistic distributions of output variables. We also analyzed the response surfaces of the dependent variables in relation to the uncertain input variables. The major conclusions are as follows.

(1) $\mathrm{R}^{2}$ values larger than 0.9 and NRMSE values less than $5 \%$ indicate that the developed response surface models are acceptable and reliable for the predicting the physical behavior of the $\mathrm{CO}_{2}$-EOR system at the FWU.

(2) The large $90^{\text {th }}$ percentile intervals (differences between $5^{\text {th }}$ and $95^{\text {th }}$ percentiles) of emulated cumulative oil production, net $\mathrm{CO}_{2}$ storage, net water stored, and pressure buildup suggest that a significant proportion of forecasted output response uncertainty, including forecasted storage capacity, was propagated from parameter uncertainties.

(3) When the permeability ranges from 10.0 to $31.6 \mathrm{mD}$ (close to the mean actual value in situ), the cumulative oil production will be maximum. The effects of permeability on net $\mathrm{CO}_{2}$ storage is opposite to those for cumulative oil production.

(4) The high pressure build-up at the lower permeability zone may result in caprock fracturing given that the pressure threshold of $36.5 \mathrm{MPa}$ for the caprock at the FWU.

In summary, the results of this study provide a quantitative forecast of uncertainties of $\mathrm{CO}_{2}$ storage and oil recovery and potential risks (e.g., pressure buildup) based on the 5-year $\mathrm{CO}_{2}$-EOR operation/test data in the Farnsworth. The 5-year test provides valuable field data for reservoir characterization and multiphase flow parameter estimation. The established reservoir model and the RSM approach could be used with 
Monte Carlo sampling to predict the storage performance and pressure distribution for $>50$ years within the probabilistic framework in future studies.

\section{ACKNOWLEDGEMNT}

The work has been supported by the Phase III Southwest Partnership on Carbon Sequestration (SWP) Farnsworth $\mathrm{CO}_{2}$-EOR project funded by the U.S. Department of Energy through the National Energy Technology Laboratory, under the auspices of Project \# DE-FC26-05NT42591. The research of the first author is partly supported by the Utah Science Technology and Research Initiative (USTAR). We would like to thank Drs. Robert Balch and Reid Grigg at New Mexico Institute of Mining and Technology, Dr. Mark White at Pacific Northwest National Laboratory, and Dr. Martin Appold at University of Missouri for their support and help on the 3-D reservoir simulations. We also thank Dr. Dongbin Xiu at University of Utah for his theoretical support on the RSM approach.

\section{REFERENCES}

Ampomah, W., R.S. Balch, and R.B. Grigg, 2015. Analysis of upscaling algorithms in heterogeneous reservoirs with different recovery processes. SPE Production Operations Symposium, Oklahoma City, Oklahoma, March 1-5.

Ampomah, W., R.S. Balch, R.B. Grigg, R. Will, Z. Dai, and M.D. White, 2016. Farnsworth field $\mathrm{CO}_{2}$-EOR project: Performance case history. Proceedings of SPE Improved Oil Recovery Conference, SPE-179528-MS, Tulsa, Oklahoma, April 11-13. 
Ashraf, M., S. Oladyshkin, and W. Nowack, 2013. Geological storage of $\mathrm{CO}_{2}$ : Application, feasibility and efficiency of global sensitivity analysis and risk assessment using the arbitrary polynomial chaos. International Journal of Greenhouse Gas Control, http://dx.doi.org/10.1016/j.ijggc.2013.03.023.

Bacon, D., N. Qafoku, Z. Dai, E. Keating, C. Brown, 2015. Modeling the Impact of Carbon Dioxide Leakage into an Unconfined, Oxidizing Carbonate Aquifer. International Journal of Greenhouse Gas Control, doi:10.1016/j.ijggc.2015. 04.008 .

Box, G.E.P., and K. B. Wilson, 1951. On the experimental attainment of optimum conditions (with discussion). Journal of the Royal Statistical Society Series B, 13(1): 1-45.

Dai, Z., H. Viswanathan, J. Fessenden-Rahn, R. Middleton, F. Pan, W. Jia, S.Y. Lee, B.J. McPherson, W. Ampomah, and R. Grigg, 2014a. Uncertainty quantification for $\mathrm{CO}_{2}$ sequestration and enhanced oil recovery. Energy Procedia, 43: 7685-7693.

Dai, Z., R. Middleton, H. Viswanathan, J. Fessenden-Rahn, J. Baman, R. Pawar, S.Y. Lee, and B.J. McPherson, 2014b. An integrated framework for optimization $\mathrm{CO}_{2}$ sequestration and enhanced oil recovery. Environmental Science \& Technology Letters, 1: 49-54.

Dai, Z., P. H. Stauffer, J. W. Carey, R. S. Middleton, Z. Lu, J. F. Jacobs, K. HnottavangeTelleen, L. Spangle, 2014c. Pre-site characterization risk analysis for commercialscale carbon sequestration. Environmental Science \& Technology, 48: 3908-3915.

Deng, H., P.H. Stauffer, Z. Dai, Z. Jiao, and R.C. Surdam, 2012. Simulation of industrialscale $\mathrm{CO}_{2}$ storage: Multi-scale heterogeneity and its impacts on storage capacity, 
injectivity and leakage. International Journal of Greenhouse Gas Control, 10: $397-418$.

Ferreira, S.L.C., R.E. Bruns, E.G.P. de Silva, W.N.L. dos Santos, C.M. Quintella, J.M. David, J.B. de Andrade, M.C. Breitkretiz, I.C.S.F. Jardim, and B.B. Neto, 2007. Statistical designs and response surface techniques for the optimization of chromatographic systems. Journal of Chromatography A, 1158: 2-14.

Ghanem, R., and P.D. Spanos, 1991. Stochastic finite elements: a spectral approach. Springer-Verlag, New York.

Ghomian, Y., K. Sephrnoori, and G.A. Pope, 2010. Efficient investigation of uncertainties in flood design parameters for coupled $\mathrm{CO}_{2}$ sequestration and enhanced oil recovery. SPE International Conference on $\mathrm{CO}_{2}$ Capture, Storage, and Utilization, November 10-12, 2010, New Orleans, Louisiana, USA.

Gallagher, S.R., 2014. Depositional and diagenetic controls on reservoir heterogeneity: Upper Morrow sandstone, Farnsworth Unit, Ochiltree County, Texas. M.S. Thesis, New Mexico Institute of Mining and Technology. Socorro, New Mexico.

Li., S. and Y. Zhang, 2014. Model complexity in carbon sequestration: A design of experiment and response surface uncertainty analysis. International Journal of Greenhouse Gas Control, 22: 123-138.

Liu, B., and Y. Zhang, 2011. $\mathrm{CO}_{2}$ modeling in a deep saline aquifer: A predictive uncertainty analysis using design of experiment. Environmental Science \& Technology, 45: 3504-3510. 
Myers, R.H., and D.C. Montgomery, 2012. Response surface methodology: Processes and product optimization using designed experiments. Second Edition, John Wiley \& Sons, Inc.

Munson, T.W., 1989. Depositional, diagenetic, and production history of the Upper Morrow Buckhaults sandstone, Farnsworth Field, Ochiltree County, Texas. Shale Shaker, 40(1): 2-20.

Oladyshin, S., H. Class, R. Helmig, and W. Nowak, 2011. A concept for data-driven uncertainty quantification and its application to carbon dioxide storage in geological formations. Advances in Water Resources, 34: 1508-1518.

Oladyshkin, S., H. Class, R. Helmig, and W. Nowak, 2010. Highly efficient tool for probabilistic risk assessment of CCS joint with injection design. XVIII Conference on Water Resources, Barcelona, Spain.

Pan, F., M. Ye, J. Zhu, Y.S. Wu, B.X. Hu, and Z. Yu, 2009a. Incorporating layer- and local-scale heterogeneities in numerical simulation of unsaturated flow and tracer transport. Journal of Contaminant Transport, 103: 194-205.

Pan, F., M. Ye, J. Zhu, Y.S. Wu, B.X. Hu, and Z. Yu, 2009b. Numerical evaluation of uncertainty in water retention parameters and effect on predictive uncertainty. Vadose Zone Hydrology, 8(1): 158-166.

Rohmer, J., and O. Bouc, 2010. A response surface methodology to address uncertainties in cap rock failure assessment for $\mathrm{CO}_{2}$ geological storage in deep aquifers. International Journal of Greenhouse Gas Control. 4: 198-208.

Tian, H., F. Pan, T. Xu, B.J. McPherson, G. Yue, and P. Mandalaparty, 2014. Impacts of hydrological heterogeneities on caprock mineral alteration and containment of 
$\mathrm{CO}_{2}$ in geological storage sites. International Journal of Greenhouse Gas Control, 23: $30-42$.

Schlumberger, 2012. ECLIPSE reservoir simulation software, 2012.1 Manuals.

Wainwright, H. M., S. Finsterle, Q. Zhou, and J.T. Birkholzer, 2013. Modeling the performance of large-scale $\mathrm{CO}_{2}$ storage systems: a comparison of different sensitivity analysis methods. International Journal of Greenhouse Gas Control 17: 189-205.

Wiener, N. 1938. The homogeneous chaos. American Journal of Mathematics, 60(4): 897-936.

White, M.D., B.J. McPherson, R.B. Grigg, W. Ampomah, and M.S. Appold, 2014. Numerical simulation of carbon dioxide injection in the western section of the Farnsworth Unit. Energy Procedia, 63: 7891-7912.

Wriedt, J., M. Deo, W.S. Han, and J. Lepinski, 2014. A methodology for quantifying risk and likelihood of failure for carbon dioxide injection into deep saline reservoirs. International Journal of Greenhouse Gas Control, 20: 196-211.

Xiu, D., and G.E. Karniadakis, 2002. The Wiener-Askey polynomial chaos for stochastic differential equations. SIAM J. Sci. Comput., 24(2):619-644.

Yang, C., Z. Dai, K. Romanak, S. Hovorka, R. Trevino, 2014. Inverse Modeling of Water-Rock- $\mathrm{CO}_{2}$ Batch Experiments: Implications for Potential Impacts on Groundwater Resources at Carbon Sequestration Sites, Environmental Science \& Technology, 48 (5), 2798-2806.

Yao, Y., and Z. Ji, 2010. A quick evaluation model for $\mathrm{CO}_{2}$ flooding and sequestration. Petroleum Science, 7(4): 515-523. 
Ye, M., F. Pan, Y.S. Wu, B.X. Hu, C. Shirley, and Z. Yu, 2007. Assessment of radionuclide transport uncertainty in the unsaturated zone of Yucca Mountain. Advances in Water Resources, 30: 118-134.

Zhang, Y. and N.V. Sahinidis, 2013. Uncertianty quantification in $\mathrm{CO}_{2}$ sequestration using surrogate models from polynomial chaos expansion. Industrial \& Engineering Chemistry Research, 52: 3121-3132. 


\section{Tables and Figures}

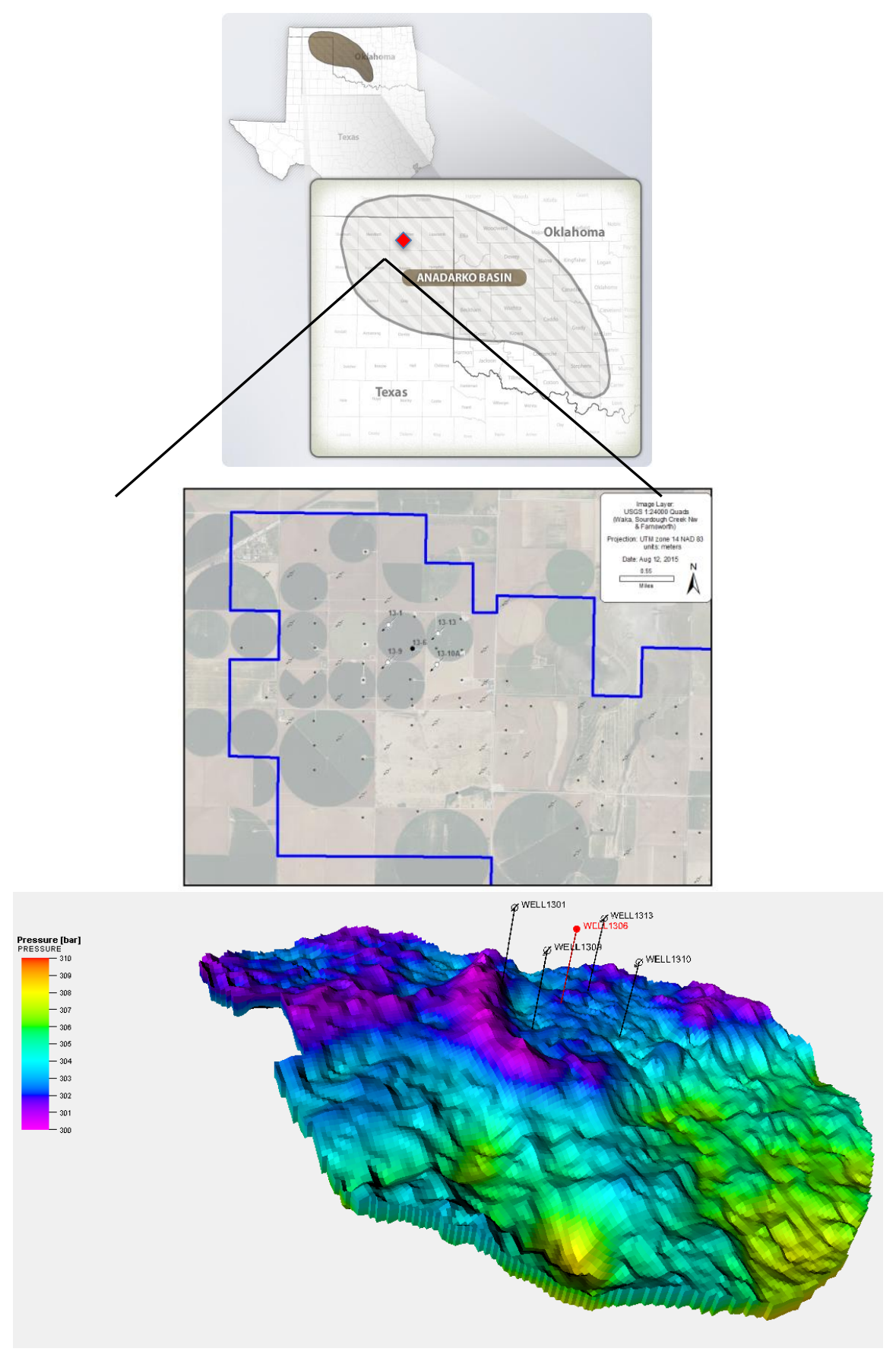

Figure 1. The location of Farnsworth Unit (FWU) within the Anadarko Basin, the west half domain of FWU, and 3-D static reservoir model domain used for this study. 


\section{Porosity-Permeability at Well 13-10}

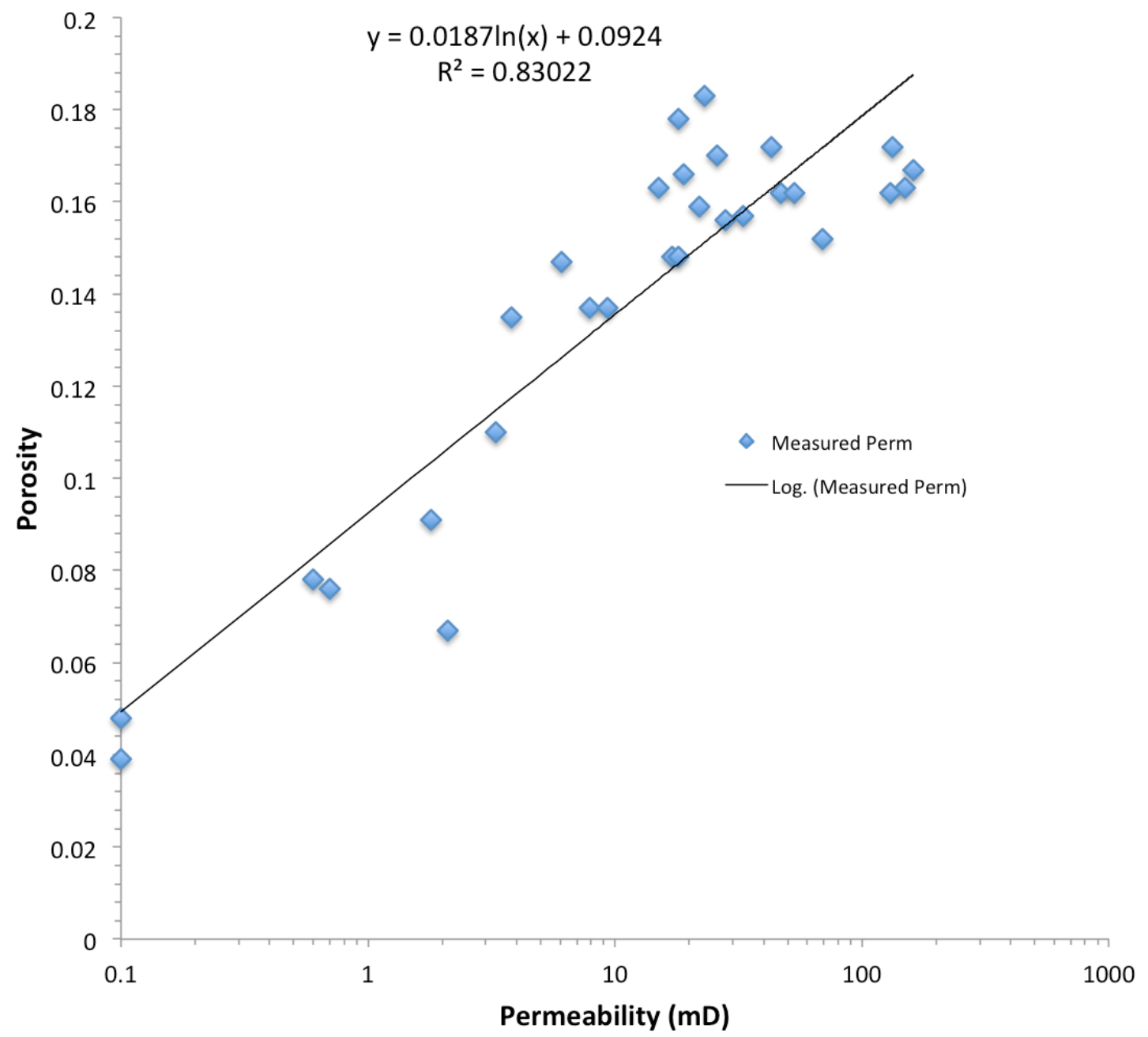

Figure 2 . The empirical relationship between the porosity and permeability at Well \#13-10 on west side of the FWU. 

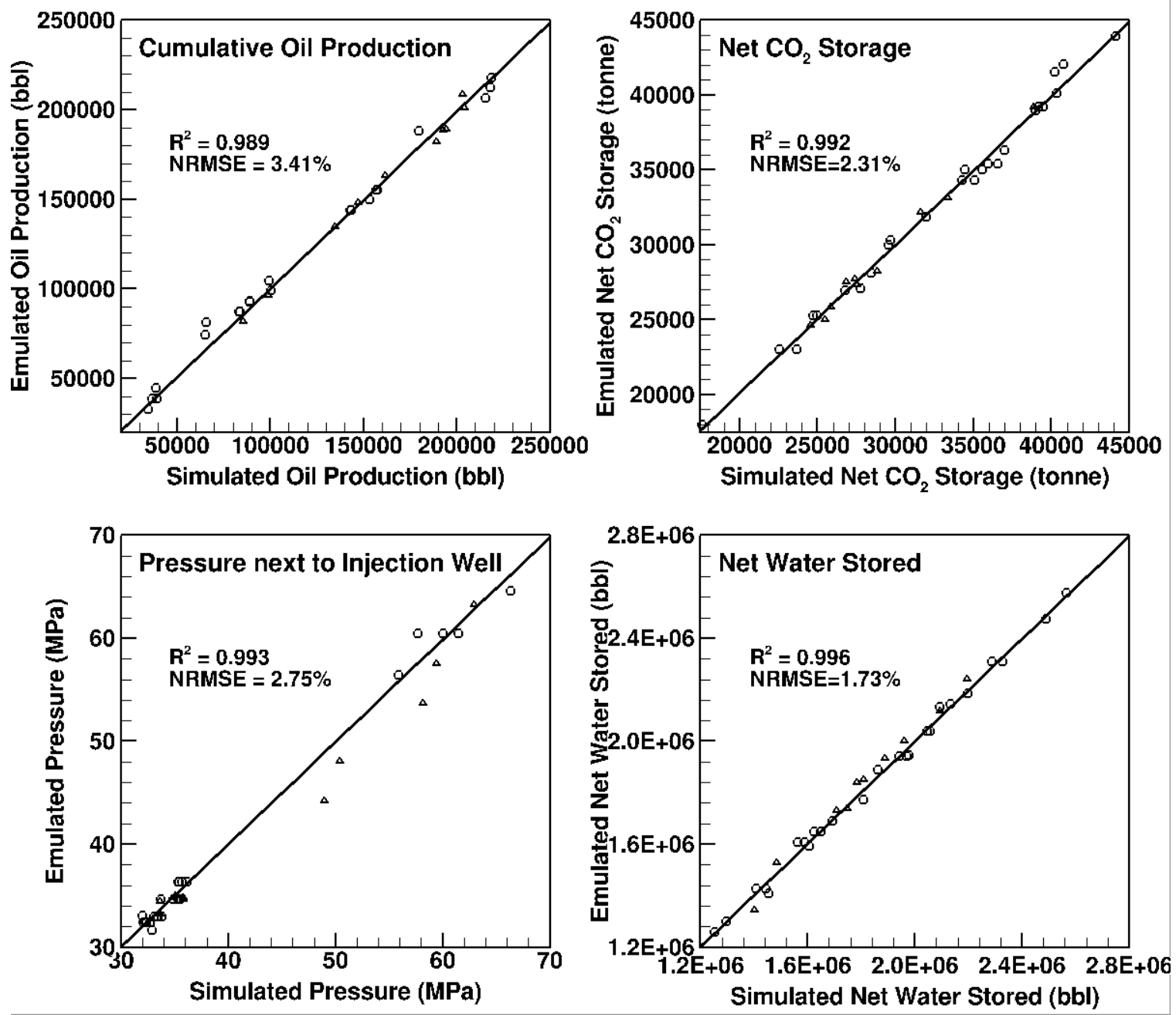

Figure 3. The simulated (using reservoir model, dot) and emulated (using response surface models, line) cumulative oil production, net $\mathrm{CO}_{2}$ storage, net water stored, and pressure next to the injection well after 5 years of simulation. 

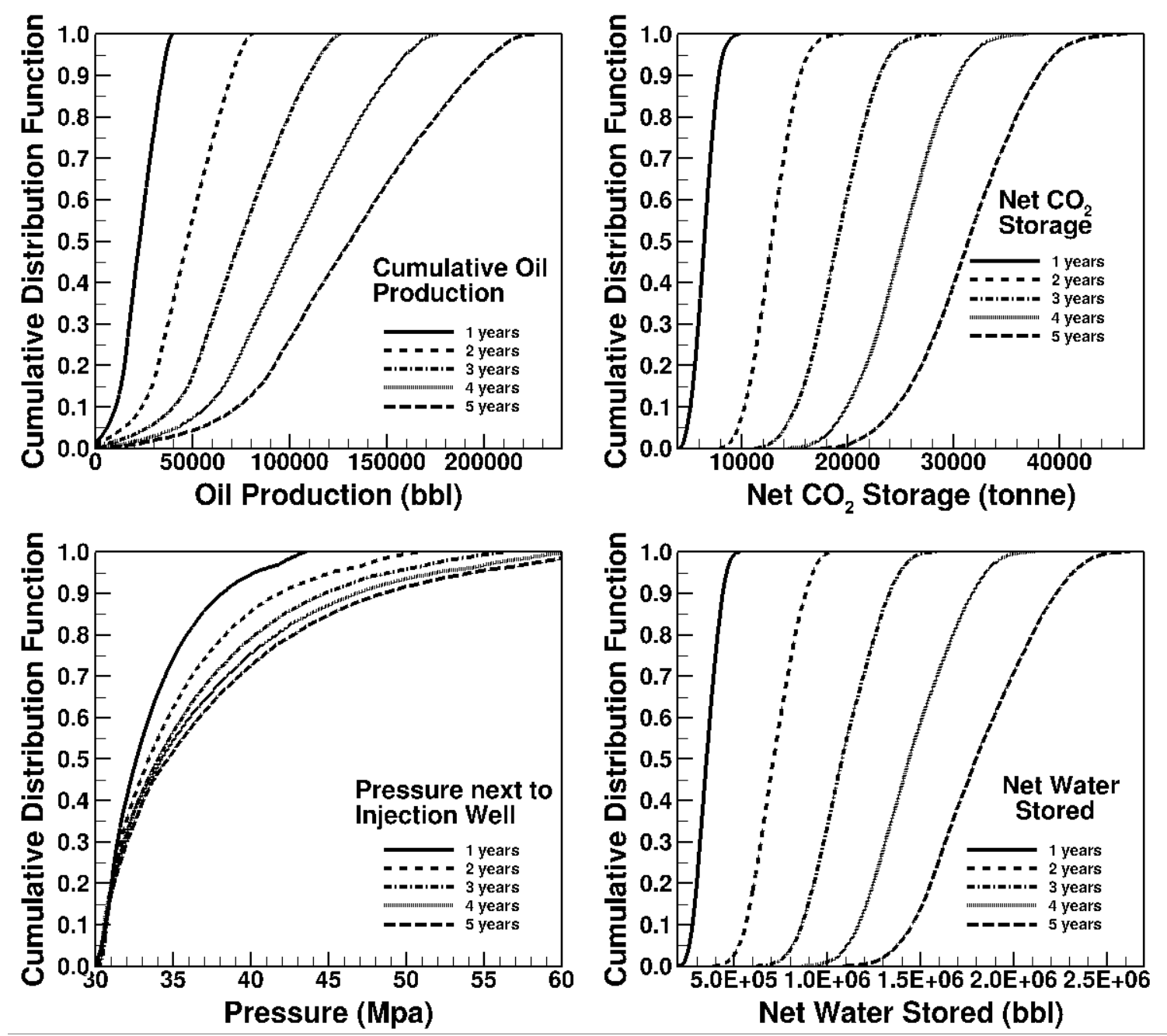

Figure 4. The cumulative distribution functions (CDFs) of emulated cumulative oil production, net $\mathrm{CO}_{2}$ storage, net water stored, and pressure next to the injection well after 1, 2, 3, 4, and 5 years of water- $\mathrm{CO}_{2}$ injection. 

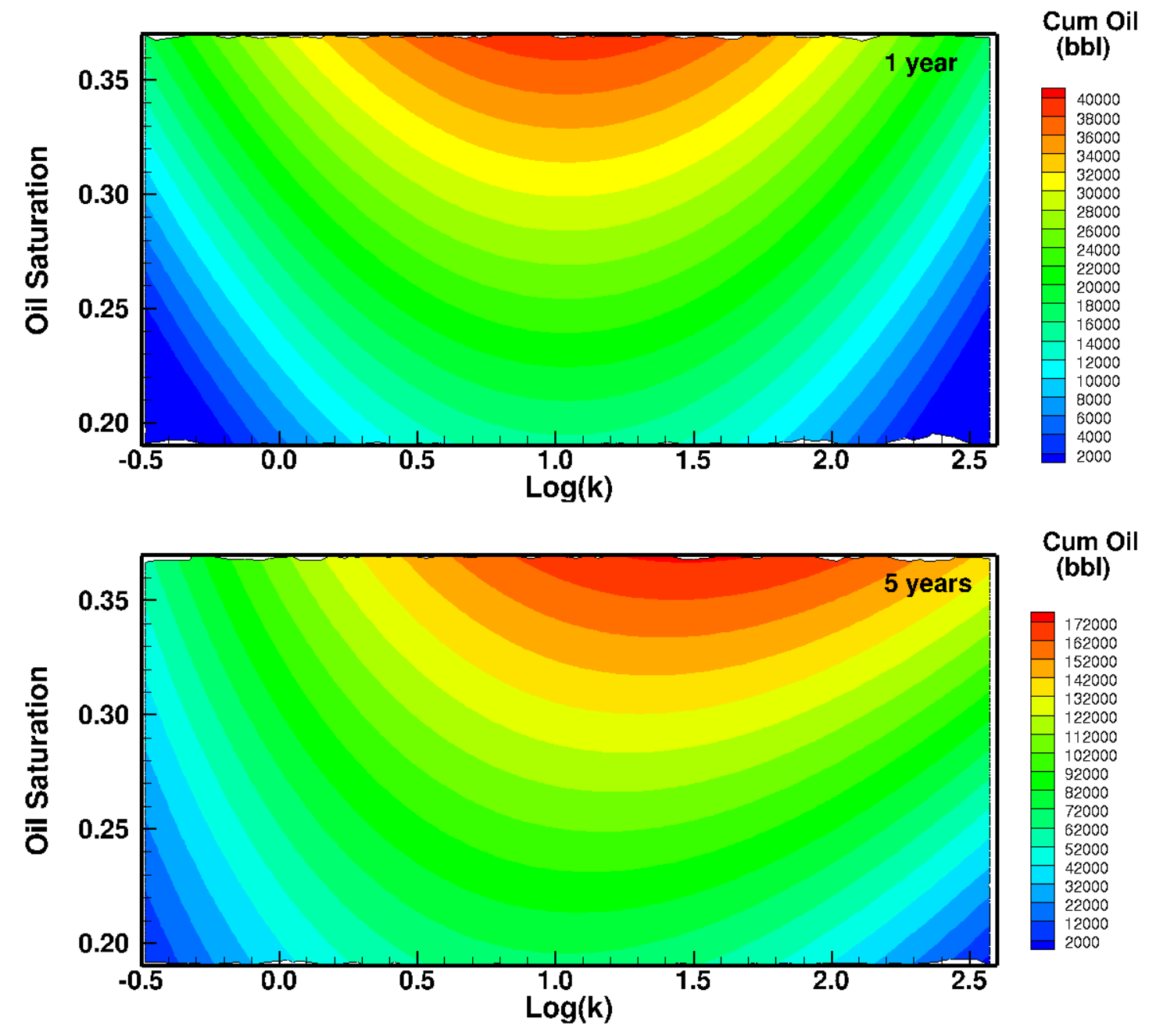

Figure 5. The response surface of cumulative oil production after 1 year (top) and 5 years (bottom) of water-alternating- $\mathrm{CO}_{2}$ injection in relation to the uncertain input variables of log permeability and initial oil saturation. 


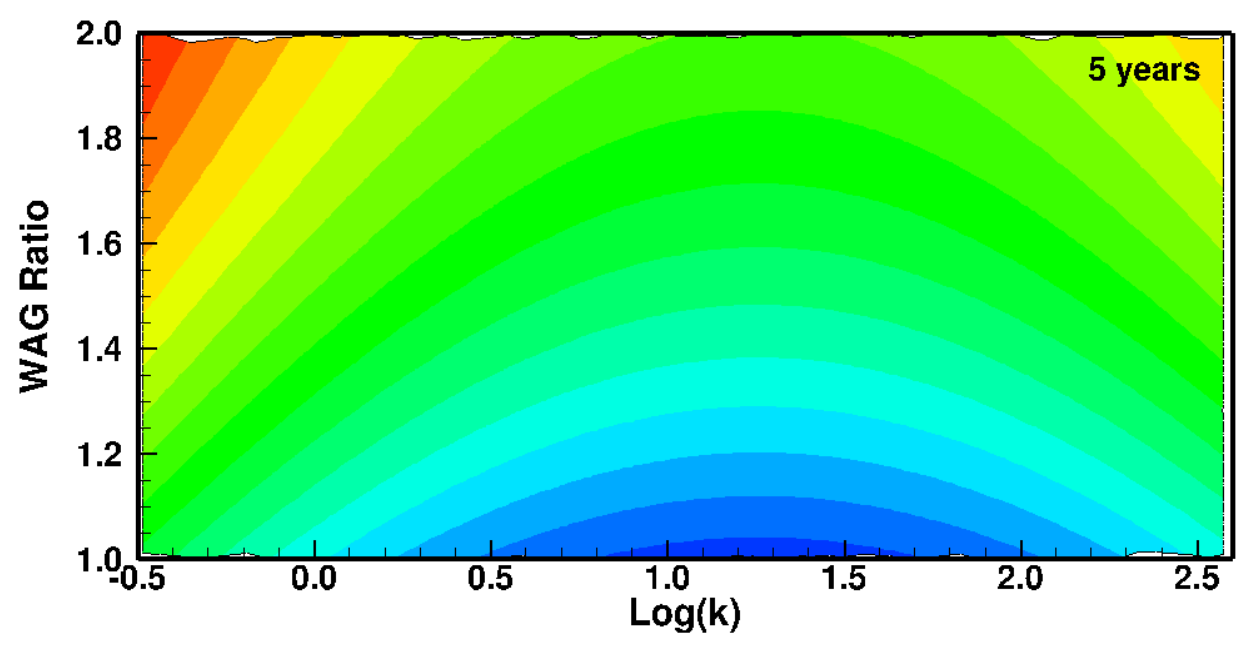

$\begin{gathered}\text { Net CO} \\ \text { (tonne) }\end{gathered}$
$\begin{aligned} & 35000 \\ & 34000 \\ & 33000 \\ & 32000 \\ & 31000 \\ & 30000 \\ & 29000 \\ & 28000 \\ & 27000 \\ & 26000 \\ & 25000 \\ & 24000 \\ & 23000 \\ & 22000 \\ & 21000 \\ & 20000 \\ & 19000 \\ & 18000\end{aligned}$

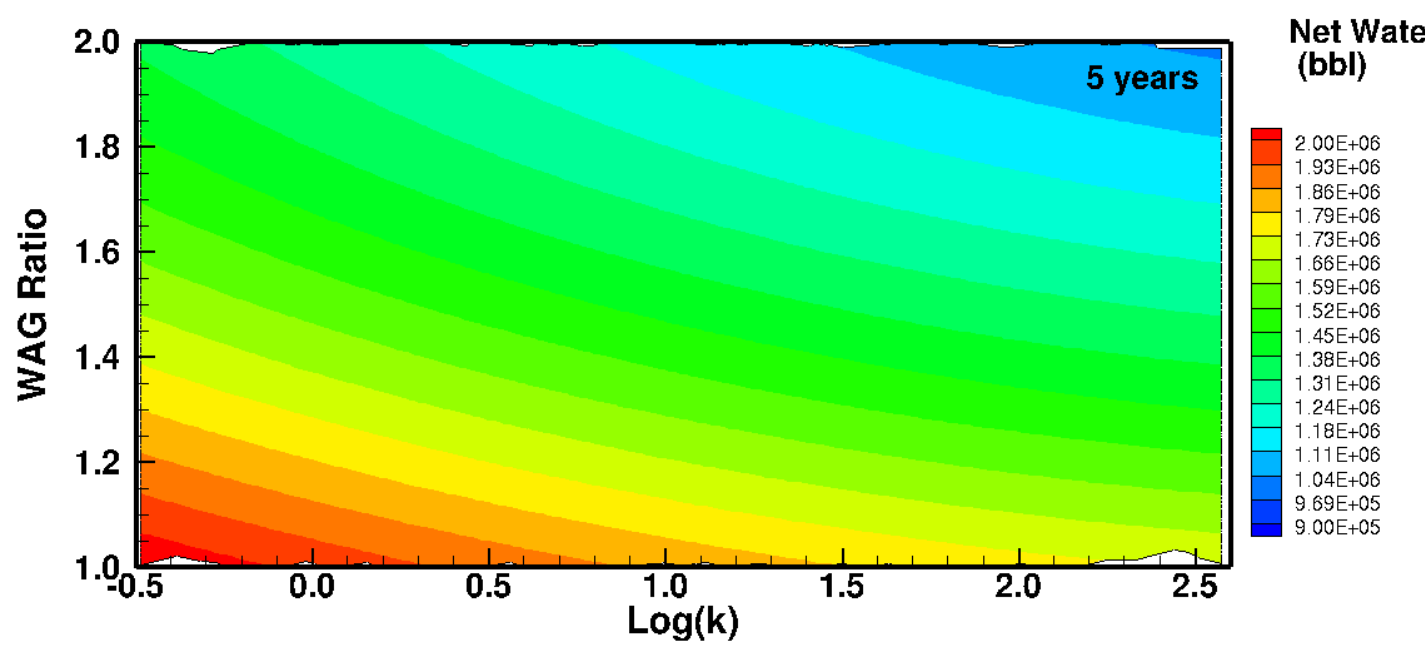

Figure 6. The response surface of net $\mathrm{CO}_{2}$ storage (top) and net water stored (bottom) after 5 years of water-alternating- $\mathrm{CO}_{2}$ injection in relation to the uncertain input variables of log permeability and WAG ratio. 


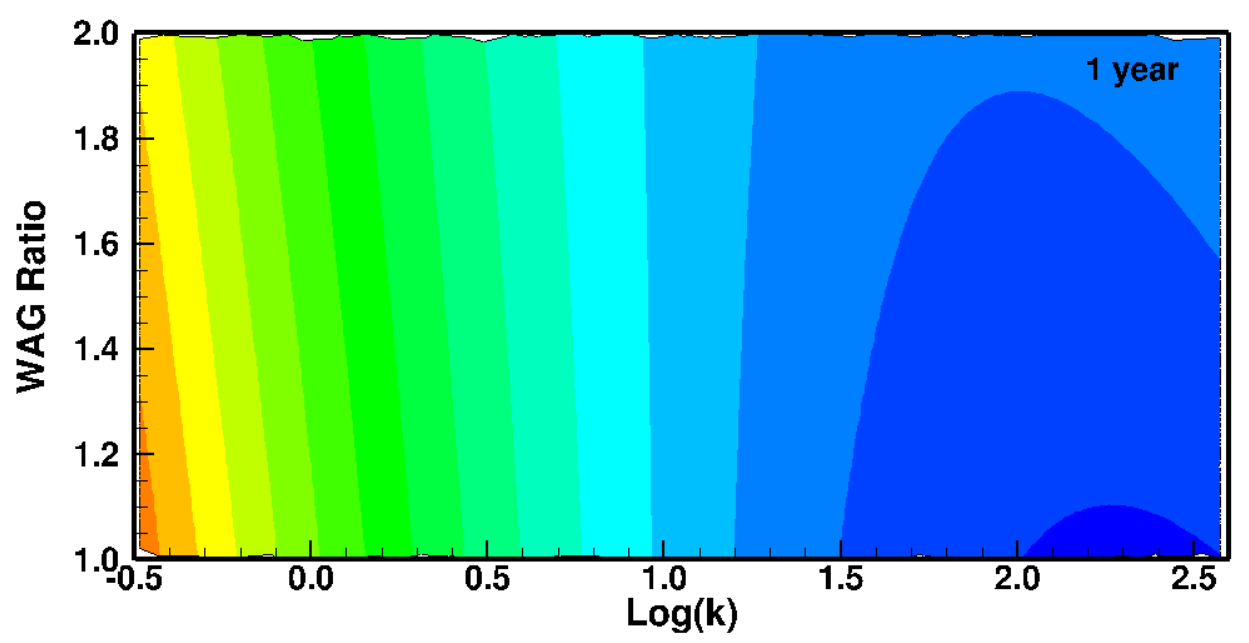

Pressure

(Mpa)

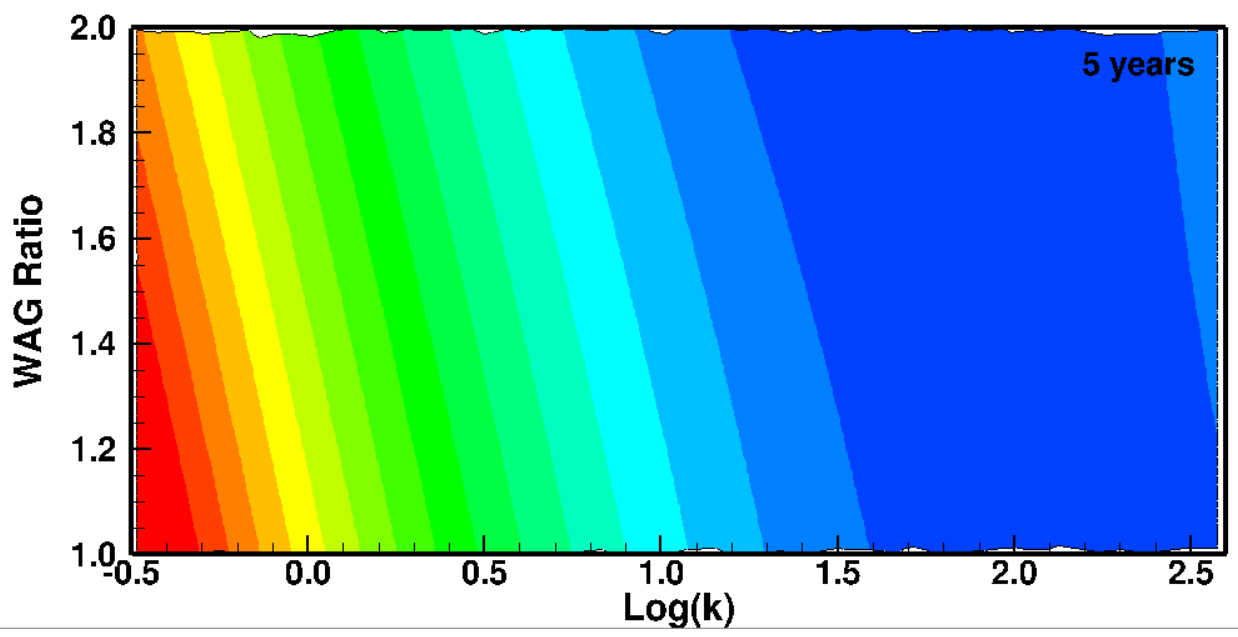

Pressure

(Mpa)

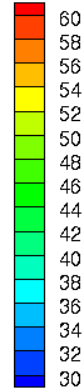

Figure 7. The response surface of pressure next to the injection well after 1 year (top) and 5 years (bottom) of water-alternating- $\mathrm{CO}_{2}$ injection in relation to the uncertain input variables of log permeability and WAG ratio. 
Table 1. The uncertain independent variables assigned in the design of the numerical experiment.

\begin{tabular}{|l|c|c|c|c|c|}
\hline \multicolumn{2}{|c|}{ Independent variables (Xi) } & Low(-1) & Mid (0) & High(+1) & $\begin{array}{c}\text { Statistical } \\
\text { Distribution }\end{array}$ \\
\hline X1 & Permeability (mD) & 0.33 & 11.07 & 374.97 & Log-normal \\
\hline X2 & Anisotropy ratio (Kv $\left./ \mathrm{K}_{\mathrm{h}}\right)$ & 0.1 & 0.55 & 1.0 & Uniform \\
\hline X3 & $\begin{array}{c}\text { WAG time ratio (CO } \\
\text { injection time/water } \\
\text { injection time) }\end{array}$ & 1.0 & 1.5 & 2.0 & Uniform \\
\hline X4 & Initial oil saturation & 0.19 & 0.28 & 0.37 & Uniform \\
\hline
\end{tabular}

Table 2. Lists of $5^{\text {th }}, 25^{\text {th }}, 5^{\text {th }}, 75^{\text {th }}$, and $95^{\text {th }}$ percentiles of the output responses.

\begin{tabular}{|c|c|c|c|c|c|c|c|c|}
\hline \multirow{2}{*}{$\begin{array}{l}\text { Output } \\
\text { Responses } \\
\text { Percentiles }\end{array}$} & \multicolumn{2}{|c|}{$\begin{array}{l}\text { Cumulative oil } \\
\text { production } \\
\text { (bbl) }\end{array}$} & \multicolumn{2}{|c|}{$\begin{array}{l}\text { Net } \mathrm{CO}_{2} \\
\text { storage } \\
\text { (tonne) }\end{array}$} & \multicolumn{2}{|c|}{$\begin{array}{l}\text { Net water stored } \\
\text { (bbl) }\end{array}$} & \multicolumn{2}{|c|}{$\begin{array}{l}\text { Pressure } \\
\text { buildup } \\
\text { (Mpa) }\end{array}$} \\
\hline & 1 year & $\begin{array}{c}5 \\
\text { years }\end{array}$ & 1 year & $\begin{array}{c}5 \\
\text { years }\end{array}$ & 1 year & 5 years & $\begin{array}{c}1 \\
\text { year }\end{array}$ & $\begin{array}{c}5 \\
\text { years }\end{array}$ \\
\hline $\begin{array}{l}5^{\text {th }} \\
\text { percentile }\end{array}$ & 5,866 & 54,696 & 4,858 & $\begin{array}{c}22,78 \\
4\end{array}$ & $\begin{array}{c}260,6 \\
58\end{array}$ & $\begin{array}{c}1,373,17 \\
0,\end{array}$ & 30.40 & 30.48 \\
\hline $\begin{array}{l}25^{\text {th }} \\
\text { percentile }\end{array}$ & $\begin{array}{c}16,34 \\
4\end{array}$ & 98,182 & 5,779 & $\begin{array}{c}27,81 \\
4\end{array}$ & $\begin{array}{c}310,3 \\
73\end{array}$ & $\begin{array}{c}1,595,42 \\
8 \\
\end{array}$ & 31.23 & 31.59 \\
\hline $\begin{array}{l}50^{\text {th }} \\
\text { percentile }\end{array}$ & $\begin{array}{c}22,79 \\
7 \\
\end{array}$ & $\begin{array}{c}131,06 \\
1\end{array}$ & 6,492 & $\begin{array}{c}31,39 \\
0\end{array}$ & $\begin{array}{c}354,1 \\
61\end{array}$ & $\begin{array}{c}1,797,06 \\
1\end{array}$ & 32.64 & 34.66 \\
\hline $\begin{array}{l}75^{\text {th }} \\
\text { percentile }\end{array}$ & $\begin{array}{c}29,76 \\
0\end{array}$ & $\begin{array}{c}166,69 \\
8\end{array}$ & 7,232 & $\begin{array}{c}35,12 \\
5\end{array}$ & $\begin{array}{c}402,3 \\
39\end{array}$ & $\begin{array}{c}2,044,50 \\
2\end{array}$ & 40.24 & 40.79 \\
\hline $\begin{array}{l}95^{\text {th }} \\
\text { percentile }\end{array}$ & $\begin{array}{c}36,36 \\
8\end{array}$ & $\begin{array}{c}203,98 \\
9\end{array}$ & 8,227 & $\begin{array}{c}39,52 \\
5\end{array}$ & $\begin{array}{c}460,9 \\
42\end{array}$ & $\begin{array}{c}2,316,56 \\
4\end{array}$ & 32.65 & 54.19 \\
\hline
\end{tabular}

